\title{
Effects of vitamin C and magnesium L-threonate treatment on learning and memory in lead-poisoned mice
}

\author{
Kemajl Bislimi ${ }^{1}$, Ilir Mazreku ${ }^{1 凶}$, Jeton Halili $^{4}$, \\ Valbona Aliko ${ }^{3}$, Kushtrim Sinani ${ }^{2}$, Liridon Hoxha ${ }^{5}$ \\ ${ }^{1}$ Faculty of Math and Natural Sciences, Department of Biology, \\ ${ }^{4}$ Faculty of Math and Natural Sciences, Department of Chemistry, \\ University of Prishtina "Hasan Prishtina", 10000 Prishtina, Kosovo \\ ${ }^{2}$ Faculty of Life Sciences, University of Bradford, Bradford BD7 1DP, United Kingdom \\ ${ }^{3}$ Faculty of Natural Science, Department of Biology, University of Tirana, 1029 Tirana, Albania \\ Faculty of Science, University of Konstanz, 78457 Konstanz, Germany \\ ilir.mazreku@uni-pr.edu
}

Received: November 27, $2020 \quad$ Accepted: May 21, 2021

\begin{abstract}
Introduction: The aim of this study was to investigate the effects of vitamin C (vit C) and magnesium L-threonate (MgT) on the learning ability and memory of mice intoxicated with lead acetate. Material and Methods: The experimental male Swiss albinos were divided into five groups of 10 during a 40-day treatment period. One group were untreated controls, one received lead acetate at $90 \mathrm{mg} / \mathrm{kg}$ b.w., one additionally vit C at $40 \mathrm{mg} / \mathrm{kg}$ b.w., another additionally $\mathrm{MgT}$ at $100 \mathrm{mg} / \mathrm{kg}$ b.w., and the last was administered MgT without lead acetate. After a 20-day washout period, the animals were trained in the Morris water maze test for 6 days and after a 24-hour interval, were assessed for memory in the same test. At test end the mice were sacrificed and their organs sampled. Results: The results of total time and number of entries into the platform zone showed that significantly poorer performances were recorded for the group poisoned with lead acetate alone and significantly lower scores for learning and memory were recorded for the intoxicated and supplemented groups compared to the control group. Catalase activity was significantly reduced in the liver, pancreas and kidney but significantly potentiated in brain tissue by these two supplements compared to the control group. Lead concentration in brain tissue was significantly higher in the presence of vit $\mathrm{C}$ than in the control or lead acetate-only groups. Conclusion: Lead acetate had adverse effects on learning and memory of mice and also increased catalase activity.
\end{abstract}

Keywords: enzyme, intoxication, lead, supplements.

\section{Introduction}

Lead is a heavy metal natural element with toxic properties, widely distributed in the environment, and still mined and added in some parts of the world to many different products including paints, eye cosmetics, and aviation fuel; it may also still be present in older water pipes. It is the cause of one of the most serious global health problems wherever communities are involved in activities such as lead smelting, gold mining, and lead battery manufacturing and recycling (28).

Lead is not an essential metal and has no biological role or function in the body, so it uses the transport proteins of other metals, such as calcium (Ca) and magnesium $(\mathrm{Mg})$, to pass through the cell membrane. The membrane transport protein, known as divalent metal transporter 1 (DMT1) and divalent cation transporter 1 (7), is present in neurons and cerebral capillary endothelial cells and is thought to non-selectively transport divalent metal ions, including $\mathrm{Mn}^{2+}, \mathrm{Fe}^{2+}, \mathrm{Co}^{2+}$, $\mathrm{Ni}^{2+}$, and $\mathrm{Cu}^{2+}(27)$. Most of the effects of lead in neural tissue come from the substitution of $\mathrm{Ca}^{2+}$ and $\mathrm{Mg}^{2+}$ by this metal. The blood-brain barrier (BBB) has long been known as a target for lead toxicity. Under conditions of lead exposure, an increase in pinocytotic activity and changes in the characteristic endothelial tight junctions resulted in microvascular damage to it (30). Successfully crossing the BBB, inorganic compounds of lead accumulate significantly in the hippocampus and cause memory and learning disorders (17).

The hippocampus is the locus of synaptic routes thought to be the main ones for encoding new memories. 
A decrease in hippocampal long-term potentiation (a phenomenon of synaptic plasticity by which recent activity strengthens synapses in a persistent way) leads to impaired memory, whereas an increase in it correlates with improved memory and learning (12). Learning and memory are major functions of the brain that are affected by several factors, including some which are dietary and environmental (lead exposure being one), and some which are genetic. Many supplements on the market claim to improve these functions, through various metabolic approaches. One, vitamin C, has been found to be less abundant in individuals with impaired cognition (24). Another, magnesium L-threonate, is commonly used as a storage supplement to increase magnesium levels in plasma and cerebrospinal fluid (CSF) and has been suggested as having the capacity to improve short-term synaptic plasticity and long-term potentiation (21). These supplements are investigated for their supportiveness of cognitive functions after lead intoxication in the present study.

The accumulation of reactive oxygen species (ROS) is controlled in vivo by two metabolic systems: nonenzymatic antioxidant systems such as glutathione (GSH), bilirubin, vitamins E, A, and C, and defencerelated enzymes such as catalase (CAT), glutathione peroxidase, and superoxide dismutase (SOD) (11). Catalase activity is induced by exposure of animal species to metal as an environmental characteristic or as chemical pollution (25). Vitamin $\mathrm{C}$ has shown a protective role in heavy metal intoxication marked by decreased CAT activity (20). Alternate antioxidant enzyme CAT activity is stimulated by increased $\mathrm{Mg}$ levels and this element thereby exerts a protective effect against heavy metal intoxication $(4,13)$. Vitamin $C$ and ethylenediaminetetraacetic acid (EDTA) have also been studied for their chelating properties in lead-poisoned organisms and both had similar effects as chelating agents of lead (6). Ascorbic acid has also been used as the main treatment for lead poisoning (19).

The two compounds vitamin $\mathrm{C}$ and magnesium L-threonate were assessed for their capacity to alleviate memory and learning deficiencies in a murine model intoxicated with the most bio-available form of lead, lead acetate.

\section{Material and Methods}

Materials. Lead acetate in trihydrate form and of reagent grade at $99.5 \%$ purity was ordered from LächNer (Neratovice, Czech Republic). Vitamin C (L-ascorbic acid, 99\%), primary and secondary sodium phosphate $(99.9 \%)$, and hydrogen peroxide $(99 \%)$ were from Sigma-Aldrich, (Taufkirchen, Germany). Magnesium L-threonate as the product Magtein was procured from Swanson Vitamins, (Fargo, ND,). Double-distilled water was produced and used in all our experiments. The feed for the animals came from Veterinarski Zavod (Subotica, Serbia).
Animals and treatment. A total of 50 6-month-old male Mus musculus of the Swiss albino strain weighing from $30 \mathrm{~g}$ to $40 \mathrm{~g}$ were obtained from the vivarium of the Laboratory of Animal Behaviour in the Faculty Natural Science and Mathematics of the University of Prishtina in Kosovo. The animals were divided into five equal groups and each animal was housed in an individual cages after a two-week acclimation period. All conditions in the vivarium were in accordance with international rules (Directive 2010/63/EU). The diet of the animals consisted of tap water and prepared mouse food with $23 \%$ protein. The first group of animals served as a control group, while three groups were treated with $90 \mathrm{mg} / \mathrm{kg} \mathrm{b.w}$. doses of lead acetate (group $\mathrm{Pb}$ ), lead acetate and $40 \mathrm{mg} / \mathrm{kg}$ b.w. vitamin $\mathrm{C}$ (group $\mathrm{Pb}+$ vit $\mathrm{C}$ ), and lead acetate and $100 \mathrm{mg} / \mathrm{kg}$ b.w. magnesium L-threonate (group $\mathrm{Pb}+\mathrm{MgT}$ ) and the final group only with $100 \mathrm{mg} / \mathrm{kg}$ b.w. magnesium L-threonate (group MgT). The doses of lead acetate, magnesium L-threonate and vitamin $\mathrm{C}$ were calculated each day after measuring the body weight of the animal and administered for 40 days as the treatment period. In addition to body weight, food and water intake per day were recorded. Any changes observed in the behaviour of the mice were also noted. Lead acetate and vitamin $\mathrm{C}$ were diluted in drinking water, and magnesium L-threonate was added to the diet. After these 40 treatment days, there was a 20-day washout period during which the animals were fed a normal diet. During the washout period the Morris water maze (MWM) test was conducted and data were recorded with AnyMaze software (Stoelting Co, Wood Dale, IL, USA). Animals were euthanised on the last day of the washout phase. The liver, brain, kidneys and pancreas were collected, weighed, and placed in cold sodium phosphate buffer (concentration $0.05 \mathrm{M}$ and $\mathrm{pH}$ 7.0) until they were homogenised using an OV5 Homogenizer (Velp Scientifica, Usmate, Italy). The homogenates were centrifuged at 5,000 rpm for 10-15 min and then the supernatant was transferred to new sterile test tubes and stored at $4^{\circ} \mathrm{C}$. Enzyme activity was measured within $24 \mathrm{~h}$. Total protein concentration was measured in diluted organ homogenates according to the Lowry method, using bovine serum as the standard. Enzyme activity for CAT was calculated as $\mathrm{UI} / \mathrm{mg}$ protein.

Morris water maze. The water maze test was performed in a circular black pool $120 \mathrm{~cm}$ in diameter containing water at a temperature of $24 \pm 2{ }^{\circ} \mathrm{C}$ that had been coloured with a nontoxic brown dye to contrast with the mice. A $10-\mathrm{cm}$-diameter round brown platform was placed $1.0 \mathrm{~cm}$ above (on days $1 \& 2$ of the trial) or below (on days 3-6 of the trial) the water surface. On the first two days, with the platform visible, the mice were allowed to remain on the platform for $20 \mathrm{~s}$ before the experiment began. On subsequent days, the mice were given a maximum time of $60 \mathrm{~s}$ to find the hidden platform, and they were allowed to remain on it for $20 \mathrm{~s}$. The mice were directed to land on the platform if they could not find the platform within $60 \mathrm{~s}$. The mice were 
given nine trials daily for six consecutive days and the swimming pathway and latency in locating the hidden platform were recorded for each trial. The seventh day was a $24 \mathrm{~h}$ rest period before memory tests were performed. On the eighth day, the number of crossings, the latency to enter the quadrant where the platform had been for the first time and the total time spent in the target quadrant were recorded with the platform removed. These three parameters are the main data we used to measure spatial memory retrieval.

Enzyme analysis (estimation of CAT activity). Enzyme activity was measured to assess oxidative stress and cellular damage in the liver, brain, kidneys and pancreas of lead-poisoned animals and the effects of treatment with vitamin $\mathrm{C}$ and magnesium L-threonate.

Total catalase activity was determined spectrophotometrically with a UV-VIS 1240 Mini Spectrophotometer (Shimadzu, Kyoto, Japan) by following the decline in absorbance at $240 \mathrm{~nm}$ as $\mathrm{H}_{2} \mathrm{O}_{2}$ $\left(\mathrm{E}=36 \mathrm{M}^{-1} \mathrm{~cm}^{-1}\right.$ ) was catabolised according to the method of Nilsson (14). The accuracy and sensitivity of the method were estimated by measuring bovine catalase levels at various activity levels, from 3 to 450 units (IU).

Lead concentration. Brain tissue was mineralised after chemical oxidation with nitric acid and hydrogen peroxide treatment and thermal decomposition at $450^{\circ} \mathrm{C}$ for $8 \mathrm{~h}$. Lead concentration was measured with a ContrAA 800D atomic absorption spectrometer (Analytic Jena, Jena, Germany). The curve of measurements was standard with concentrations of $0 \mathrm{mg} / \mathrm{L}, 0.5 \mathrm{mg} / \mathrm{L}, 1 \mathrm{mg} / \mathrm{L}, 1.5 / \mathrm{mg} / \mathrm{L}$ and $2 \mathrm{mg} / \mathrm{L}$ and values of 0.9997 for $\mathrm{R}^{2}, 0.0107 \mathrm{mg} / \mathrm{L}$ for limit of detection, and $0.0320 \mathrm{mg} / \mathrm{L}$ for limit of quantification.

Statistical analysis. Learning and memory were analysed by AnyMaze software (Stoelting Co., Wood Dale, IL, USA), using one-way ANOVA fixed factor analysis and the Student-Newman-Keuls test. Enzyme activity data were analysed using Microsoft Excel one-way ANOVA to compare the five groups, then Student's $t$-test was used as a post-hoc test. Results were reported as mean $\pm \mathrm{SD}$. Differences were considered statistically significant at a probability level of $<0.05$.

\section{Results}

Catalase activity levels were calculated as mean values per mg protein of the samples. In all organ samples, we observed a significant $(\mathrm{P}<0.05$ for liver, pancreas, and brain and $\mathrm{P}<0.001$ for kidney) difference in CAT activity between the control group and group $\mathrm{Pb}$. Group $\mathrm{Pb}$ also showed a significantly increased CAT activity in liver, pancreas and kidney samples when compared with groups $\mathrm{Pb}+$ vit $\mathrm{C}, \mathrm{Pb}+\mathrm{MgT}$ and $\mathrm{MgT}$. Brain catalase activity was increased in groups $\mathrm{Pb}+$ vit $\mathrm{C}$ and $\mathrm{Pb}+\mathrm{MgT}$ compared with group $\mathrm{Pb}$. The increased effect of lead acetate toxicity in the brain after treatment with vit $\mathrm{C}$ and $\mathrm{MgT}$ is shown by increased levels of catalase activity in the brain tissue compared with the group intoxicated with lead acetate and not administered supplements (Table 1).

The daily measured body weight and water and food intake (Table 2) of the animals did not change significantly during the treatment.

After dissection, the organs were weighed, and the results are presented in Table 3. After statistical calculation, there were no significant differences in organ weight.

Learning trials. Measurements of performance in learning trials in the MWM began with latency (time from start to goal). Figure 1 shows latency time results calculated as trial block means (nine trials per day). All groups intoxicated with lead acetate (groups $\mathrm{Pb}, \mathrm{Pb}+$ vit $\mathrm{C}$ and $\mathrm{Pb}+\mathrm{MgT})$ had longer latency times $(\mathrm{P}<0.05)$ on the sixth and final day compared to the groups not given the intoxicant. The longest latency times were recorded for group $\mathrm{Pb}+$ vit $\mathrm{C}$. When the group $\mathrm{Pb}+$ vit $\mathrm{C}$ and group $\mathrm{Pb}$ results were compared, we found a significantly longer latency time for the supplemented group. Group $\mathrm{Pb}+\mathrm{MgT}$ did not show any divergence from group $\mathrm{Pb}$.

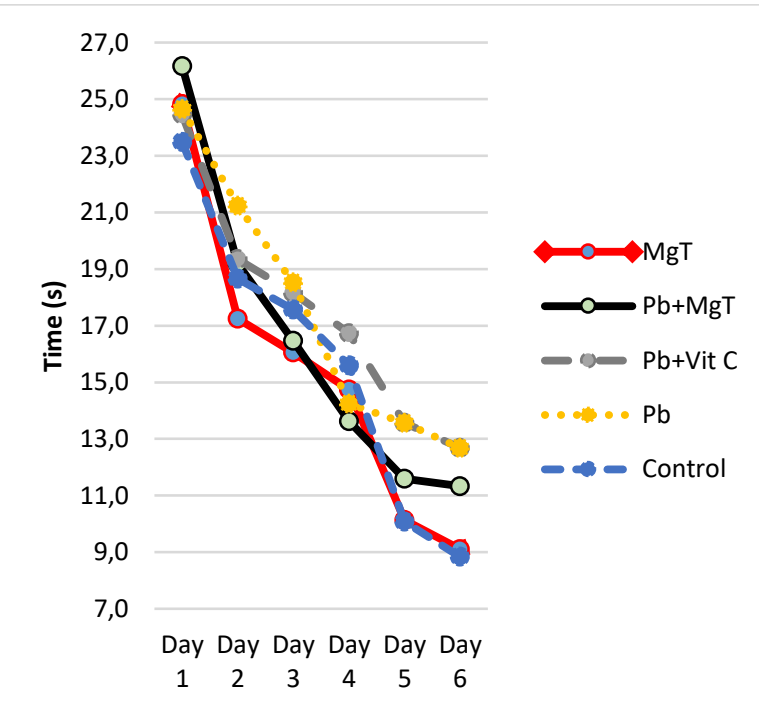

Fig. 1. Latency or time from the start of the trial to the platform entry. Data were calculated as the mean of blocks of trials (nine trials per day)

Vit $\mathrm{C}$ - vitamin C; MgT - magnesium L-threonate

Memory testing. Memory was measured using three different parameters. After six days of training in the water maze, serving as learning time, they mice had one day $(24 \mathrm{~h})$ to rest. The eighth day was the test day and nine trials were carried out for each mouse without the platform for $60 \mathrm{~s}$ with $30 \mathrm{~min}$ resting time between trials. The data in Figs 2, 3, and 4 represent results from the water maze test.

Latency to the first entry into the platform zone. In Fig. 2, we present the latency times to the first entry into the platform zone as the mean of blocks of trials (nine trials per day). The average times of groups $\mathrm{Pb}+$ vit $\mathrm{C}$ and $\mathrm{Pb}+\mathrm{MgT}$ were higher than those of group $\mathrm{MgT}$ and the control group. A significantly $(\mathrm{P}<0.05)$ longer time was taken by group $\mathrm{Pb}+$ vit $\mathrm{C}$ mice than by group $\mathrm{Pb}$ mice. 


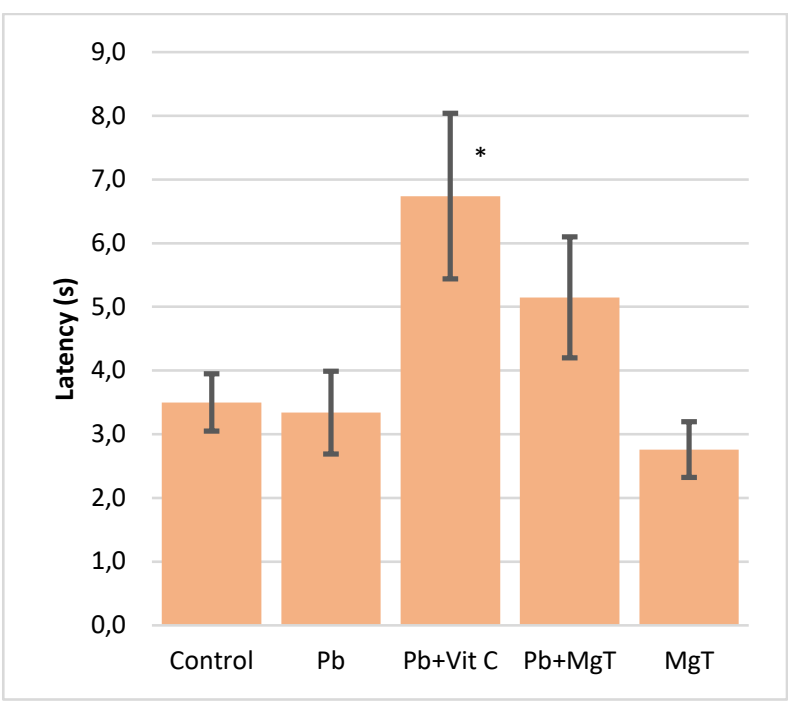

Fig. 2. Latency to first entry into the platform zone. Data were calculated as the mean of blocks of trials (nine trials per day) Vit C - vitamin C; MgT - magnesium L-threonate

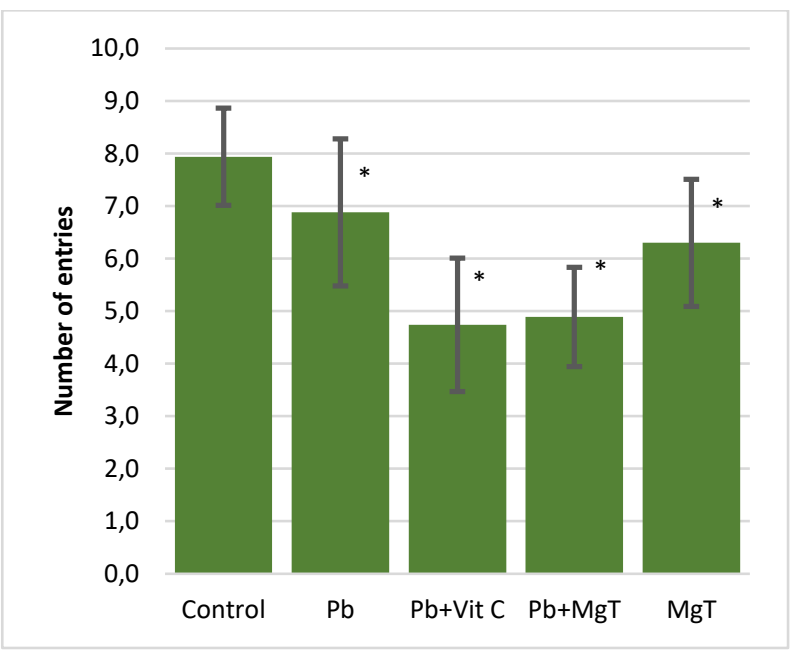

Fig. 3. Number of entries in the platform zone (line crossing). Data were calculated as the mean of blocks of trials (nine trials per day) Vit C - vitamin C; MgT - magnesium L-threonate

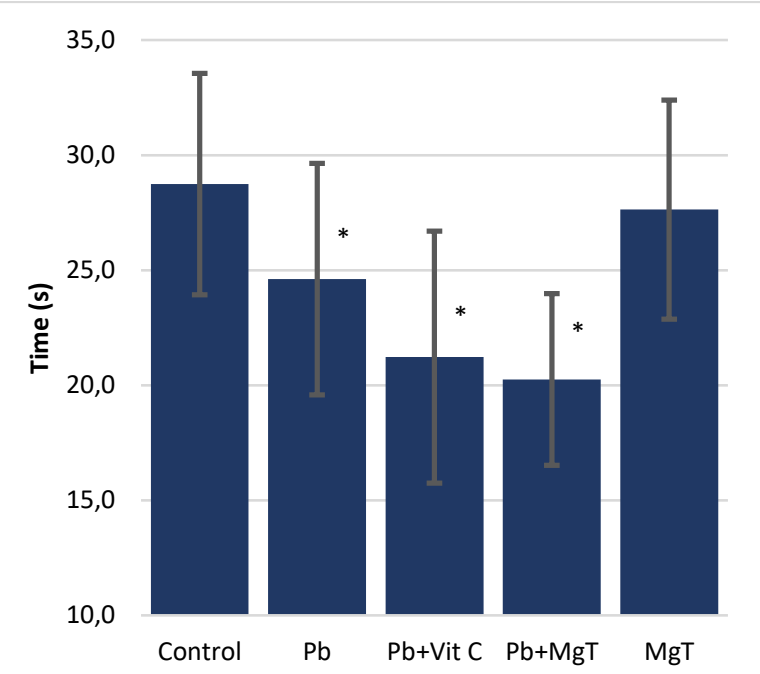

Fig. 4. Time in the platform zone. Data were calculated as the mean of blocks of trials (nine trials per day)

Vit C - vitamin C; MgT - magnesium L-threonate
Number of entries to the platform zone (line crossings). In Fig. 3 we present the number of entries into the platform zone. These are how many times the border was crossed of the zone where the platform was located during the learning trials; the values are means of blocks of trials. These results are similar to the latency results. Groups $\mathrm{Pb}+$ vit $\mathrm{C}$ and $\mathrm{Pb}+\mathrm{MgT}$ demonstrated a significantly $(\mathrm{P}<0.05)$ lower number of line crossing compared with the control group and groups $\mathrm{Pb}$ and $\mathrm{MgT}$. The lower number of line crossings of group MgT compared with the group intoxicated only with lead acetate and not administered supplements is explained by the average time spent in the platform zone, as shown in Fig. 4.

Time in the platform zone. In Fig. 4, we present the total time spent in the platform zone. These values are how long was spent per mouse and are mean durations calculated for blocks of trials. The groups intoxicated with lead acetate (groups $\mathrm{Pb}, \mathrm{Pb}+\mathrm{vit} \mathrm{C}$ and $\mathrm{Pb}+\mathrm{MgT})$ spent significantly $(\mathrm{P}<0.01)$ less time in the platform zone than the control group or group MgT. Animals treated with magnesium L-threonate (group $\mathrm{MgT}$ did not show any significant variation as either an improvement or impairment of spatial memory compared with the control group. Group $\mathrm{Pb}+$ vit $\mathrm{C}$ and group $\mathrm{Pb}+\mathrm{MgT}$ mice spent significantly $(\mathrm{P}<0.01)$ less time in the platform zone than group $\mathrm{Pb}$ mice.

We also measured the lead concentration in the brain. The concentration levels of lead in different groups of mice are shown in Table 4.

Lead concentration in the brains of animals intoxicated with lead acetate was significantly higher than in the brains of control group animals. The highest levels of lead were found in group $\mathrm{Pb}+$ vit $\mathrm{C}$. On the other hand, group $\mathrm{Pb}+\mathrm{MgT}$ showed a significantly lower concentration of lead in the brain than groups $\mathrm{Pb}$ and $\mathrm{Pb}+$ vit $\mathrm{C}$.

When we analysed correlations we found high correspondence between CAT activity in the brain and the number of entries into the platform zone and latency to the first entry into the platform zone (0.91 and 0.67 , respectively). A very high correlation values (0.87) was found also between lead concentration in the brain and the memory parameters mentioned above.

\section{Discussion}

Our research findings are consistent with studies by other authors. Catalase is one of the most important enzymes for antioxidant protection of cells. It is found mainly in hepatocytes and erythrocytes, but is present in almost all cell types in the animal body. Hepatocytes and erythrocytes were the cells in which the measured CAT activity was highest (10). When rats were treated per os with sublethal doses of lead acetate, an increase in CAT activity was found in the liver and kidney compared with this activity in the control group rat organs, along with other metabolic changes (9). 
Table 1. Catalase activity level (CAT IU/mg protein) in Swiss albino mouse liver, kidney, pancreas and brain tissue after administration of lead acetate

\begin{tabular}{|c|c|c|c|c|c|c|}
\hline & \multicolumn{6}{|c|}{ Group } \\
\hline & & Control $(\mathrm{n}=10)$ & $\mathrm{Pb}(\mathrm{n}=10)$ & $\mathrm{Pb}+\mathrm{Vit} \mathrm{C}(\mathrm{n}=10)$ & $\mathrm{Pb}+\operatorname{MgT}(\mathrm{n}=10)$ & $\operatorname{MgT}(\mathrm{n}=10)$ \\
\hline \multirow{4}{*}{ Organ } & Liver & $222.5 \pm 45.61$ & $501.8 \pm 70.10^{*}$ & $229.3 \pm 54.13$ & $250.2 \pm 81.52$ & $204.9 \pm 50.02$ \\
\hline & Pancreas & $18.5 \pm 8.98$ & $51.2 \pm 16.12 *$ & $31.3 \pm 17.54$ & $26.3 \pm 13.22$ & $37.3 \pm 16.75$ \\
\hline & Kidney & $97.3 \pm 34.56$ & $269.1 \pm 55.89 * *$ & $124.6 \pm 43.54$ & $105.3 \pm 52.23$ & $130.5 \pm 42.54$ \\
\hline & Brain & $3.9 \pm 2.86$ & $8.1 \pm 3.05^{*}$ & $9.3 \pm 3.67 *$ & $8.9 \pm 3.11^{*}$ & $4.4 \pm 2.26$ \\
\hline
\end{tabular}

Vit $\mathrm{C}$ - vitamin $\mathrm{C} ; \mathrm{MgT}-$ magnesium L-threonate; $* \mathrm{P}<0.05, * * \mathrm{P}<0.001$ compared to control

Table 2. Average values of body weight and food and water intake during the 40 days of treatment

\begin{tabular}{lcccc}
\hline Group & $\begin{array}{c}\text { Initial average } \\
\text { body weight }(\mathrm{g})\end{array}$ & $\begin{array}{c}\text { Terminal average } \\
\text { body weight }(\mathrm{g})\end{array}$ & $\begin{array}{c}\text { Average daily } \\
\text { food intake }(\mathrm{g})\end{array}$ & 6.89 \\
\hline $\mathrm{Control}$ & 35.24 & 35.05 & 3.01 & 6.21 \\
\hline $\mathrm{Pb}$ & 33.34 & 36.97 & 6.07 & 6.51 \\
\hline $\mathrm{Pb}+\mathrm{Vit} \mathrm{C}$ & 32.24 & 35.69 & 6.78 & 6.11 \\
\hline $\mathrm{Pb}+\mathrm{MgT}$ & 33.52 & 35.91 & 3.12 & 6.15 \\
\hline $\mathrm{MgT}$ & 34.04 & 37.12 & 6.52 \\
\hline
\end{tabular}

Vit C - vitamin C; MgT - magnesium L-threonate

Table 3. Average organs weights in grams (liver, kidney, pancreas and brain) of mice (Mus musculus Swiss albino) after dissection

\begin{tabular}{|c|c|c|c|c|c|c|}
\hline & \multicolumn{6}{|c|}{ Group } \\
\hline & & Control $(n=10)$ & $\mathrm{Pb}(\mathrm{n}=10)$ & $\mathrm{Pb}+\mathrm{Vit} \mathrm{C}(\mathrm{n}=10)$ & $\mathrm{Pb}+\mathrm{MgT}(\mathrm{n}=10)$ & $\operatorname{MgT}(\mathrm{n}=10)$ \\
\hline \multirow{4}{*}{ Organ } & Liver & $1.02 \pm 0.29$ & $0.89 \pm 0.08$ & $0.93 \pm 0.16$ & $0.92 \pm 0.49$ & $1.11 \pm 0.26$ \\
\hline & Pancreas & $0.20 \pm 0.10$ & $0.17 \pm 0.07$ & $0.23 \pm 0.07$ & $0.15 \pm 0.10$ & $0.17 \pm 0.05$ \\
\hline & Kidney & $0.38 \pm 0.16$ & $0.50 \pm 0.08$ & $0.56 \pm 0.12$ & $0.55 \pm 0.10$ & $0.43 \pm 0.10$ \\
\hline & Brain & $0.35 \pm 0.03$ & $0.36 \pm 0.05$ & $0.35 \pm 0.02$ & $0.36 \pm 0.02$ & $0.36 \pm 0.04$ \\
\hline
\end{tabular}

Vit C - vitamin C; MgT - magnesium L-threonate

Table 4. Lead concentration $(\mathrm{mg} / \mathrm{kg})$ in the brains of mice treated with different combinations of chemicals

\begin{tabular}{lllll}
\hline & \multicolumn{4}{c}{ Group } \\
\hline Parameter & Control $(\mathrm{n}=10)$ & $\mathrm{Pb}(\mathrm{n}=10)$ & $\mathrm{Pb}+\mathrm{Vit} \mathrm{C}(\mathrm{n}=10)$ & $\mathrm{Pb}+\mathrm{MgT}(\mathrm{n}=10)$ \\
\hline $\mathrm{Pb}$ & $0.35 \pm 0.001$ & $1.58 \pm 0.009 *$ & $1.67 \pm 0.039 *$ & $0.94 \pm 0.035^{*}$ \\
\hline
\end{tabular}

Vit C - vitamin C; MgT - magnesium L-threonate; * $\mathrm{P}<0.05$ compared with control

Brain CAT activity was also augmented after acute lead acetate administration in mice (2). Research on rats showed the effect of lead in relation to the activity of SOD, CAT, and other antioxidant enzymes important for the prevention of lipid peroxidation (22). Other authors (18) also reported increased levels of CAT activity in the livers, pancreas and kidneys of mice intoxicated with lead. The hepatotoxicity of heavy metals derives from their suppressive action on the levels of proteins and glutathione and facilitative effect on the synthesis of ROS species such as $\mathrm{H}_{2} \mathrm{O}_{2}, \mathrm{OH}-$ and $\mathrm{O}_{2}{ }^{2-}$. These products can cause damage to the cell membrane by peroxidation of lipids (23). Vitamin C supplementation significantly decreased GSH content, and SOD and CAT enzyme activity in lead-intoxicated animals $(5,15)$. Other studies showed that treatment with vitamin $\mathrm{C}$ decreases the level of antioxidant enzymes (3).
Changes in the activity of antioxidant enzymes are one of the first indicators of intoxication of the organism. As shown by CAT activity, vitamin $\mathrm{C}$ had a protective effect in the groups intoxicated with lead, with the exception of brain tissue. These results can be explained by the antioxidant effect of vitamin $\mathrm{C}$ and action as a chelating agent for metals in intoxicated organisms. As our research showed, magnesium L-threonate, a substance used as a dietary supplement to improve cognitive abilities (21), did not affect other organs of the body adversely.

Vitamin $\mathrm{C}$ had no antioxidant or protective role in the brains of the lead acetate group mice (Table 1, Figs 1-4). This lack of effect was demonstrated by higher levels of CAT activity in the brains of animals in the vitamin C-treated group than in those of the mice in the lead acetate poisoned and unsupplemented group 
(Table 1). Moreover, the results of learning and memory tests showed that the treatment of lead-intoxicated animals with vitamin $\mathrm{C}$ did not improve these parameters, but on the contrary, worsened them. Treatment of lead-intoxicated animals with vitamin $\mathrm{C}$ increased the concentration of lead in the brain (Table 2). Vitamin C has the main role in DMT1 overexpression (16), and the substrate profile of DMT1 includes the metal cations $\mathrm{Fe}^{2+}, \mathrm{Cd}^{2+}, \mathrm{Co}^{2+}, \mathrm{Mn}^{2+}, \mathrm{Ni}^{2+}, \mathrm{VO}^{2+}$, and $\mathrm{Pb}^{2+}$. Divalent metal transporter 1 , which is a cation membrane transporter, was involved in the transcellular transport of lead across the BBB (26). It is suggested that the increased protein transporters in the $\mathrm{BBB}$ are the mechanism for the increased lead concentrations in the brain tissue of the groups that were intoxicated with lead and treated with vitamin $\mathrm{C}$.

The levels of lead concentration in the $\mathrm{Pb}+$ vit $\mathrm{C}$ group were significantly higher than in the $\mathrm{Pb}$ group, suggesting that vitamin $\mathrm{C}$ played no role in reducing the amount of lead in the brain. There is a possibility that magnesium played a role in the transport of lead to the intestinal wall. This may have led to this decrease in lead uptake and the lower concentration of lead in the brain in the MgT group.

The present results of learning and memory tests are consistent with the reports of other authors. The effects of lead in the impairment of hippocampal function and on nervous system function were also reported by other researchers $(1,17)$. Low levels of lead exposure caused a significant dose-dependent inhibition of proliferation of neural stem cells originating from the rat ventral mesencephalon and striatum and decreased the number of microtubule-associated protein 2-positive neurons differentiated from neural stem cells originating from these regions (8). Chronic lead exposure reduced neurogenesis in the dentate gyrus of the adult rat hippocampus (29). In this study, we found impairment of learning and memory in mice that were treated with lead acetate, lead acetate and vitamin C, and lead acetate and magnesium L-threonate. Learning and memory investigation in the group treated with magnesium L-threonate yielded results which were not significantly increased and which in this aspect were not as other authors reported (21).

The pharmaceutical supplements vitamin $\mathrm{C}$ and magnesium L-threonate played a significant detoxifying role (assessed by catalase activity) in all organs exposed to lead except the brain. Vitamin $\mathrm{C}$ and magnesium L-threonate have a large involvement in membrane transport of metallic ions, and contribute to intensifying the transportation of lead into the brain tissue (Table 4). The negative effects of vitamin $\mathrm{C}$ treatment on brain function with lead exposure are also supported by the results of learning and memory assessment. In the groups treated with lead acetate alone or lead acetate plus vitamin $\mathrm{C}$, measurements showed decreased learning and memory abilities in mice. Moreover, besides the learning and memory parameters, the lead concentration parameter and CAT activity evaluation results in the brain followed the same trend.

Lead is one of the most dangerous heavy metal intoxicants of the body and especially the brain. Our findings for learning, memory and catalase activity show that even in small concentrations it has a great effect on the basic functions of the murine brain. Similar effects of lead were found in other organs (the liver, pancreas and kidney) where vitamin $\mathrm{C}$ as an antioxidant supplement had a detoxifying effect in lead-intoxicated animals. Although it is known as a detoxifying supplement, vitamin $\mathrm{C}$ had an adverse effect on lead neuro intoxication, increasing the concentration and toxicity of the heavy metal. A similar influence to that of vitamin $\mathrm{C}$ was also found for magnesium L-threonate. Further lead intoxication research will explain the molecular mechanism of these effects of vitamin $\mathrm{C}$ in the brain and to this end the continuation of research on the agency of vitamin $C$ in the transport of lead through the $\mathrm{BBB}$ is worthwhile.

Conflict of Interests Statement: The authors declare that there is no conflict of interests regarding the publication of this article.

Financial Disclosure Statement: All the funds for this research were provided by the Faculty of Natural Science and Mathematics of the University of Prishtina, Kosovo (23/01/2015, ref no. 1570 of grant award).

Animal Rights Statement: This study was undertaken after ensuring that all experimental procedures involving animals would be conducted in accordance with Law for Animal Care No. 02/L-10, and these procedures were approved by the Ethics Committee of Faculty of Medicine of the University of Prishtina (No. 1278, ref. No. 3425).

\section{References}

1. Anderson D.W., Mettil W.A., Schneider J.S.: Rearing environment, sex and developmental lead exposure modify gene expression in the hippocampus of behaviorally naïve animals. Neurochem Int 2013, 62, 510-520, doi: 10.1016/j.neuint. 2013.01.003.

2. Correa M., Miquel M., Aragon C.M.G.: Lead acetate potentiates brain catalase activity and enhances ethanol-induced locomotion in mice. Pharmacol Biochem Behav 2000, 66, 137-142, doi: 10.1016/S0091-3057(00)00204-5.

3. Diab Abdel Aziz A., Zahra M.H., Attia M.S., Shehata A.M.: Physiological and biochemical studies on the protective effect of Ficus carica leaf extract, vitamin $\mathrm{C}$ or their combination on liver toxicity induced by lead acetate in male rats. Biomed ResTher 2018, 5, 2733-2745, doi: 10.15419/bmrat.v5i10.488.

4. Djukić-Ćosić D., Ninković M., Malicević Z., Plamenac-Bulat Z., Matović V.: Effect of supplemental magnesium on the kidney levels of cadmium, zinc, and copper of mice exposed to toxic levels of cadmium. Biol Trace Elem Res 2006, 114, 281-291, doi: 10.1385/BTER:114:1:281

5. Eshginia S. Marjani A.: The effect of vitamin C on the erythrocyte antioxidant enzymes in intoxicated-lead rat offsprings. J Clin Diag Res 2013, 7, 1078-1081, doi: 10.7860/JCDR/2013/5310.3059. 
6. Goyer R. A., Cherian M.G.: Ascorbic acid and EDTA treatment of lead toxicity in rats." Life Sci 1979, 24, 433-438, doi: 10.1016/0024-3205(79)90215-7.

7. Gunshin H., Mackenzie B., Berger U.V., Gunshin Y., Romero M.F., Boron W.F., Nussberger S., Gollan J.L., Hediger M.A.: Cloning and characterization of a mammalian proton-coupled metal-ion transporter." Nature 1997, 388, 422-488, doi: 10.1038/41343.

8. Huang F., Schneider J.S.: Effects of lead exposure on proliferation and differentiation of neural stem cells derived from different regions of embryonic rat brain. Neurotoxicology 2004, 25, 1001-1012, doi: 10.1016/j.neuro.2004.03.010.

9. Ibrahim N. M., Eweis E.A., El-Beltagi H.S., Abdel-Mobdy Y.E.: Effect of lead acetate toxicity on experimental male albino rat. Asian Pac J Trop Biomed 2012, 2, 41-46, doi: 10.1016/S22211691(11)60187-1.

10. Kang M.Y., Kim H.-B., Piao C., Lee K.H., Hyun J.W., Chang I.-Y., You H.J.: The critical role of catalase in prooxidant and antioxidant function of p53. Cell Death Differ 2013, 20, 117-129, doi: $10.1038 /$ cdd.2012.102.

11. Korge P., Calmettes G., Weiss J.N.: Increased reactive oxygen species production during reductive stress: the roles of mitochondrial glutathione and thioredoxin reductases. Biochim Biophys Acta 2015, 1847, 514-525, doi: 10.1016/j.bbabio. 2015.02.012.

12. Lee Jin Suk: A molecular basis for the efficacy of magnesium treatment following traumatic brain injury in rats. J Neurotrauma 2004, 21, 549-561, doi: 10.1089/089771504774129883.

13. Liu Y., Guo Y., Wang Z., Nie W.: Effects of source and level of magnesium on catalase activity and its gene expression in livers of broiler chickens. Arch Anim Nutr 2007, 61, 292-300, doi: 10.1080/17450390701432019.

14. Nilsson K.: Spectrophotometric measurement automatization for the analysis of enzymatic processes. $\mathrm{PhD}$ Thesis, Uppsala University Faculty of Science and Technology, Uppsala, Sweden, 2010.

15. Riffel A.P.K., Santos M.C.Q., de Souza J.A., Scheid T., Horst A., Kolberg C., Belló-Klein A., Partata W.A.: Treatment with ascorbic acid and $\alpha$-tocopherol modulates oxidative-stress markers in the spinal cord of rats with neuropathic pain. Braz $\mathrm{J}$ Med Biol Res 2018, 51, e7097, doi: 10.1590/1414$431 \mathrm{X} 20177097$.

16. Scheers N.M., Sandberg A.-S.: Ascorbic acid uptake affects ferritin, Dcytb and Nramp2 expression in Caco-2 cells. Eur J Nutr 2008, 47, 401-408, doi: 10.1007/s00394-008-0741-8.

17. Schneider J. S., Anderson D.W., Talsania K., Mettil W.A., Vadigepalli R.: Effects of developmental lead exposure on the hippocampal transcriptome: influences of sex, developmental period, and lead exposure level. Toxicol Sci 2012, 129, 108-125, doi: $10.1093 /$ toxsci/kfs189.

18. Sharma S., Raguvanshi B.P., Shukla S.: Toxic effects of lead exposure in rats: involvement of oxidative stress, genotoxic effect, and the beneficial role of $\mathrm{N}$-acetylcysteine supplemented with selenium. J Environ Pathol Toxicol Oncology 2014, 33, 19-32, doi: 10.1615/JEnvironPatholToxicolOncol.2014009712.

19. Simon J.A., Hudes E.S.: Relationship of ascorbic acid to blood lead levels. JAMA 1999, 281, 2289-2293, doi: 10.1001/jama. 281.24.2289.

20. Singh S., Srivastava A., Allen T., Bhagat N., Singh N.: Identification of heavy metal toxicity-induced biomarkers and the protective tole of ascorbic acid supplementation in Channa punctatus. Int J Pharm Sci Res 2020, 11, 1098-1109, doi: 10.13040/IJPSR.0975-8232.11(3).1098-09.

21. Slutsky I., Abumaria N., Wu L.-J., Huang C., Zhang L., Li B., Zhao X., Govindarajan A., Zhao M.-G., Zhuo M., Tonegawa S., Liu G.: Enhancement of learning and memory by elevating brain magnesium. Neuron 2010, 65, 165-177, doi: 10.1016/j.neuron.2009.12.026.

22. Soltaninejad K., Kebriaeezadeh A., Minalee B., Ostad S.N., Hosseini R., Azizi E., Abdollahi M.: Biochemical and ultrastructural evidences for toxicity of lead through free radicals in rat brain. Human Experimental Toxicol 2003, 22, 417-423, doi: 10.1191/0960327103ht385oa.

23. Su L.J., Zhang J.H., Gomez H., Murugan R., Hong X., Dongxue X., Jiang F., Peng Z.-Y.: Reactive oxygen species-induced lipid peroxidation in apoptosis, autophagy, and ferroptosis. Oxid Med Cell Longev 2019, 5080843, doi: 10.1155/2019/5080843.

24. Travica, N., Ried K., Sali A., Scholey A., Hudson I., Pipingas A.: Vitamin $\mathrm{C}$ status and cognitive function: a systematic review. Nutrients 2017, 9, 2017, 960, doi: 10.3390/nu9090960.

25. Vieira, L.R., Gravato C., Soares A.M.V.M., Morgado F., Guilhermino L.: Acute effects of copper and mercury on the estuarine fish Pomatoschistus microps: linking biomarkers to behaviour. Chemosphere, 2009, 76, 1416-1427, doi: 10.1016/j.chemosphere.2009.06.005.

26. Wang Q., Luo W., Zhang W., Liu M., Song H., Chen J.: Involvement of DMT1 1 IRE in the transport of lead in an in vitro BBB model. Toxicol in Vitro 2011, 25, 991-998, doi: 10.1016/j.tiv.2009.11.006.

27. Wang X., Li G.J., Zheng W.: Upregulation of DMT1 expression in choroidal epithelia of the blood-CSF barrier following manganese exposure in vitro. Brain Res 2006, 1097, 1-10, doi: 10.1016/j.brainres.2006.04.046.

28. Were F. H., Kamau G.N., Shiundu P.M., Wafula G.A., Moturi C.M.: Air and blood lead levels in lead acid battery recycling and manufacturing plants in Kenya. J Occup Environ Hyg, 2012, 9, 340-344, doi: 10.1080/15459624.2012.673458.

29. Xiao Y., Fu H., Han X., Hu X., Gu H., Chen Y., Wei Q, Hu Q.: Role of synaptic structural plasticity in impairments of spatial learning and memory induced by developmental lead exposure in Wistar rats. PLoS One 2014, 9, e115556, doi: 10.1371/journal.pone.0115556.

30. Zheng W., Aschner M., Ghersi-Egea J.-F.: Brain barrier systems: a new frontier in metal neurotoxicological research. Toxicol Appl Pharmacol 2003, 192, 1-11, doi: 10.1016/S0041-008X(03)00251-5. 